\title{
Genetic basis for different host use in Epilachna pustulosa, a herbivorous ladybird beetle
}

\author{
HIDEKI UENO*, NAOYUKI FUJIYAMA $† \&$ HARUO KATAKURA $\dagger$ \\ Laboratory of Environmental Medicine and Informatics, Division of Bioscience, Graduate School of Environmental \\ Earth Science, Hokkaido University, Sapporo 060 and $\nmid$ Laboratory of Systematics and Evolution, Division of \\ Biological Sciences, Graduate School of Science, Hokkaido University, Sapporo 060, Japan
}

\begin{abstract}
The genetic basis for different host plant use was studied in a herbivorous ladybird beetle, Epilachna pustulosa, that exhibits interpopulational variation in host plant utilization. It usually depends on thistle, but one of the local forms occurs on both thistle and blue cohosh, which differ at the infraclass taxonomic level. In this local population, genetic association between the developmental performance on the two plants was neutral, suggesting genetic independence across the host plants. The form of reaction norms indicated some changes in relative rank position. Genetic variation among individuals on each host plant was detected. These results suggest that different genotypes are selected on different host plants and that a substantial proportion of the overall phenotypic plasticity is contributed by genotype-dependent environmental effects.
\end{abstract}

Keywords: Epilachna pustulosa, genetic correlations, host plants, reaction norms.

\section{Introduction}

The evolution of herbivore-plant interrelation has been a particularly contentious problem in ecology and genetics (Futuyma \& Peterson, 1985; Jaenike, 1990; Via, 1990). Much attention has been paid to how the host range of a herbivorous insect is determined, for this is supposed to be a clear example of the adaptation process. Adaptation to host plants is dependent on the presence and nature of genetic variation in behaviour and physiological performance. Therefore the elucidation of the genetic basis for difference in habitat use, and habitat-related fitness components, is a key to understanding the course of insect-plant interaction.

Because selection operates on the whole phenotype rather than on individual characters, the genetic covariance among characters substantially influences the overall course of evolution. In the case where both characters are under selection pressure, selection on one character can produce a selection differ-

*Correspondence. Present address: Laboratory of Biology, Faculty of Education, Niigata University, 8050 Ikarashi Ni-NoCho, Niigata 950-21, Japan. E-mail: hueno@ed.niigata-u.ac.jp ential on the second character, resulting in changes in their joint evolution (Lande, 1979; Via \& Lande, 1985). Even in the absence of direct selection, characters can undergo evolutionary changes as a result of selection on correlated characters (Lande \& Arnold, 1983; Falconer, 1989).

By regarding the fitness component on one host plant as a character and the fitness component on another host as a different character, genetic correlation between the performance across the host plants can be estimated (Via, 1984; Falconer, 1989). The evolution of insect-plant relationships is significantly influenced by this genetic correlation; with a negative genetic correlation, selection for an increase in a fitness component character on one host plant would result in a decrease in the analogous component character on the other plant species. This trade-off in the performance may further lead to the evolution of host-specialized genotypes, which are more fit in one particular habitat than other genotypes. On the other hand, with a positive genetic correlation, selection would lead to a population constitution where genotypes with high performance on one host would also show a high performance on the other. Thus, a difference 
in host habitat would cause little difference in performance among genotypes.

The form of reaction norms, patterns of phenotype distributions produced by a single genotype across environments, also has important implications for the course of insect-plant interaction. If genotypic responses to the environment differ considerably, then norms of reaction may cross, changing the ranking of phenotypes (Stearns, 1992). Under directional selection for higher growth performance, some genotypes would therefore be favoured in one plant environment and different genotypes in the other. Thus, in this way, different genotypes may be selected in different host plant habitats.

The present study uses the herbivorous ladybird beetle, Epilachna pustulosa, to investigate (1) whether different genotypes are favoured in each host plant environment, and (2) how characters are genetically correlated across host plants, i.e. whether their genetic correlations are negative and whether possible trade-off relations are implicated.

Epilachna pustulosa exhibits interpopulational variation in host plant utilization (Katakura, 1981; Hoshikawa, 1983). It usually depends on the thistle (Cirsium kamtschaticum, Asteraceae), but one of the local forms, the Sapporo form, occurs on both thistle and blue cohosh (Caulophyllum robustum, Berberidaceae), which differ at the infraclass taxonomic level. Of the previous studies concerned with insect genetic systems on closely related plant species, few detected negative genetic association (Rausher, 1984; Hare \& Kennedy, 1986; Fox, 1993). However, different evolutionary consequences might be expected when host shifts involve plants from different families (Bush, 1969). The particular interest in this study therefore was to ascertain the genetic relationship between growth performance on totally different host environments in Sapporo populations, where variation in host plant utilization is most apparent.

\section{Materials and methods}

Epilachna pustulosa is a univoltine species. Overwintered adults were collected on thistles in a suburb of Sapporo City in May and June 1994. Rearing conditions were $22^{\circ} \mathrm{C}$ and $16 \mathrm{~L}-8 \mathrm{D}$ throughout this experiment. Pairs each consisting of one male and one female were confined in separate plastic cases. Virtually all females would have copulated and stored sperm before overwintering (Katakura, 1982) and additional copulations could have been possible in late spring to early summer before collection. Hence we started the experiment after we confirmed at least three copulations for each male and female pair. This was to ensure last-male paternity; lastmale sperm precedence (P2) in this species was reported as 0.651-0.827 (Nakano, 1985). Assuming the same sperm precedence pattern for the last three successive copulations, the expected fertilization success of previous males is $0.349^{3}=0.0425$ at most and $0.173^{3}=0.00518$ at least.

For each female, 30 eggs were collected from several egg clutches. In the following statistical calculations they were regarded as full-sib progenies, assuming complete last-male paternity. Of these 30 eggs, 15 were reared on thistle and 15 on blue cohosh. Larvae were reared individually. Fresh host plant leaves were supplied every other day. Larval development period was checked daily. On the day of pupation, fresh weight was measured to $0.0001 \mathrm{~g}$ with a microbalance. After eclosion adult body length was measured under a microscope to the nearest $0.01 \mathrm{~mm}$.

A mixed-model ANOVA was performed to detect the contribution of factors to the total variation in larval performance, setting family and interaction as random, and sex and host as fixed effects. A mixed ANOVA decomposes observed variances into variance components as shown in Table 2. This analysis was performed on three variables, larval period, pupal weight and adult body length. The analysis also provides statistical tests of genetic correlations for the traits across the hosts. With the present statistical procedure, the between-family variance directly detects the covariance association term of the trait across the host environments. Mean squares with $F$-values above 97.5 per cent indicate significant positive genetic covariation, whereas $F$-values below 2.5 per cent indicate significant negative genetic covariation, at the 5 per cent level (Fry, 1992).

Two further ANOvAs were performed to evaluate the between-family variance of performance on each host plant separately.

Between full-sib family variances contain nonadditive sources of genetic variation, including dominance and maternal effects. Furthermore, these estimates may possibly be inflated by the variances of the common microenvironment in the rearing conditions. These values should therefore be regarded as approximations of genetic properties but they provide an upper limit of genetic variation.

Because genetic properties are not necessarily the same for males and females, and some phenotypic differences were actually observed for the relationship between developmental period and adult body size, genetic correlations were estimated separately for each sex. Genetic correlation of the same trait 
across the hosts was estimated as $r_{X Y}=\operatorname{Cov}(X, Y) /$ $[\operatorname{Var}(X) \operatorname{Var}(Y)]^{1 / 2}$, where $\operatorname{Cov}(X, Y)$ is the covariance of family mean of the trait reared on one host plant and family mean of the same trait reared on the other host, and $\operatorname{Var}(X)$ is the variance of the family mean in one host environment (Via, 1984). Jackknife procedure was used to calculate the correlations with their standard errors (Sokal \& Rohlf, 1981). Here the correlation was jackknifed with each family omitted once so that the total number of iterations was equal to the number of families. The correlation coefficients were $z$-transformed for jackknifing procedures and transformed back to the coefficient scale after obtaining 95 per cent confidence limits for $z$-values.

\section{Results}

A significant difference in overall survivorship of ladybirds was observed between host plants ( $G$-test of association between survivorship and host plant, $\left.G_{1}=18.2, P<0.001\right)$. Individuals reared on thistles showed higher mortality rates than those on blue cohosh (Table 1). Another $G$-test detected different survivorship rates among families $\left(G_{12}=53.1\right.$, $P<0.001)$. Developmental characters were also significantly influenced by plant resources (Table 1 ). Those reared on cohosh showed a shorter developmental duration than those on thistle. However, they achieved a larger adult body size; beetles were significantly larger in body length and heavier in pupal weight when reared on cohosh than were their siblings raised on thistles. This between-plant difference in overall tendency was observed in both males and females. Females were significantly larger and heavier than male siblings, whereas larval periods were not significantly different between the sexes. Thus females achieved a larger body size than males although the developmental periods were similar. In contrast, duration of the pupal period was not influenced by either host plant or sex. Consequently, differences in total developmental time were almost all attributable to differences in the larval period.

For all the characters estimated, larval period, pupal weight and adult body length, mixed-model ANOVAS detected significant family $\times$ host interactions. By contrast, statistical tests for genetic correlation using calculated mean squares from mixedmodel ANOVAS detected no significant positive or negative associations (Table 2 ). The actual $F$-values were larger than 1 , but not significantly so with a two-tailed $F$-test at the 5 per cent level. $F$-statistic values for 97.5 per cent and 2.5 per cent with (12, 12) degrees of freedom are $F_{0.975}=0.305$ and $F_{0.025}=3.277$, respectively.

A strong genotype $\times$ host interaction was detected by the rank correlation plot. The correlation plot for male body weight is shown in Fig. 1. Substantial changes in relative rank position were observed in some cases, and no significant rank correlations

Table 1 Percentage survival and means (standard errors) for developmental traits in the herbivorous ladybird beetle Epilachna pustulosa reared on thistle and blue cohosh

\begin{tabular}{lcc}
\hline & \multicolumn{2}{c}{ Host } \\
\cline { 2 - 3 } & Thistle & Blue cohosh \\
\hline Larval duration (days) & $25.0 \pm 0.3^{\mathrm{a}}(42)$ & $19.8 \pm 0.2^{\mathrm{b}}(57)$ \\
$\quad$ Male & $25.5 \pm 0.5^{\mathrm{a}}(37)$ & $20.1 \pm 0.2^{\mathrm{b}}(63)$ \\
$\quad$ Female & $6.1 \pm 0.1(42)$ & $6.2 \pm 0.1(57)$ \\
Pupal duration (days) & $5.9 \pm 0.2(37)$ & $6.2 \pm 0.1(63)$ \\
$\quad$ Male & $35.6 \pm 0.8^{\mathrm{a}}(42)$ & $44.2 \pm 0.6^{\mathrm{b}}(57)$ \\
$\quad$ Female & $39.9 \pm 1.1^{\mathrm{a}}(37)$ & $47.2 \pm 0.7^{\mathrm{b}}(63)$ \\
Pupal weight (mg) & & \\
$\quad$ Male & $6.116 \pm 0.044^{\mathrm{a}}(41)$ & $6.532 \pm 0.032^{\mathrm{b}}(57)$ \\
$\quad$ Female & $3.351 \pm 0.067^{\mathrm{a}}(36)$ & $6.777 \pm 0.029^{\mathrm{b}}(62)$ \\
Body length (mm) & 39.5 & 61.0 \\
$\quad$ Male & Female & \\
Survival to adult ( per cent) & &
\end{tabular}

Letters indicate significant differences $(P<0.01)$ between host plant species determined by an analysis of variance. Sample sizes are given in parentheses. 
Table 2 Analysis of variance of developmental traits in the herbivorous ladybird beetle Epilachna pustulosa reared on thistle and blue cohosh

\begin{tabular}{|c|c|c|c|c|c|c|c|c|c|c|}
\hline \multirow[b]{2}{*}{ Source } & \multirow[b]{2}{*}{ EMS } & \multicolumn{3}{|c|}{ Larval duration } & \multicolumn{3}{|c|}{ Pupal weight } & \multicolumn{3}{|c|}{ Body length } \\
\hline & & d.f. & SS & $F$ & d.f. & SS & $F$ & d.f. & SS & $F$ \\
\hline Sex & $\sigma_{\mathrm{e}}^{2}+k_{1} O_{\mathrm{s}}$ & 1 & 8.368 & 3.129 & 1 & 379.602 & $18.075^{* *}$ & 1 & 2.037 & $35.591 * *$ \\
\hline Family & $\sigma_{\mathrm{e}}^{2}+k_{2} \sigma_{\mathrm{f} \times \mathrm{h}}^{2}+k_{3} \sigma_{\mathrm{f}}^{2}$ & 12 & 218.066 & 1.571 & 12 & 1452.317 & 2.435 & 12 & 3.596 & 2.074 \\
\hline Host & $\sigma_{\mathrm{e}}^{2}+k_{4} \sigma_{\mathrm{f} \times \mathrm{h}}^{2}+k_{5} Q_{\mathrm{h}}$ & 1 & 897.654 & $77.601^{* *}$ & 1 & 2009.135 & $40.418^{* *}$ & 1 & 5.392 & $37.315^{* *}$ \\
\hline Family $\times$ host & $\sigma_{\mathrm{e}}^{2}+k_{6} \sigma_{\mathrm{f}}^{2}$ & 12 & 138.812 & $4.325^{* *}$ & 12 & 596.511 & $2.367^{* *}$ & 12 & 1.734 & $2.534^{* *}$ \\
\hline Error & $\sigma_{\mathrm{c}}^{2}$ & 172 & 460.067 & & 172 & 3612.232 & & 168 & 9.617 & \\
\hline
\end{tabular}

Expected mean squares (EMS) were calculated as a mixed model, setting host (h) and sex (s) as fixed effects and family (f) and family $\times$ host interaction $(\mathrm{f} \times \mathrm{h})$ as random effects. Constants $(k)$ vary from trait to trait depending on the total number of progeny.

$* * P<0.01$.

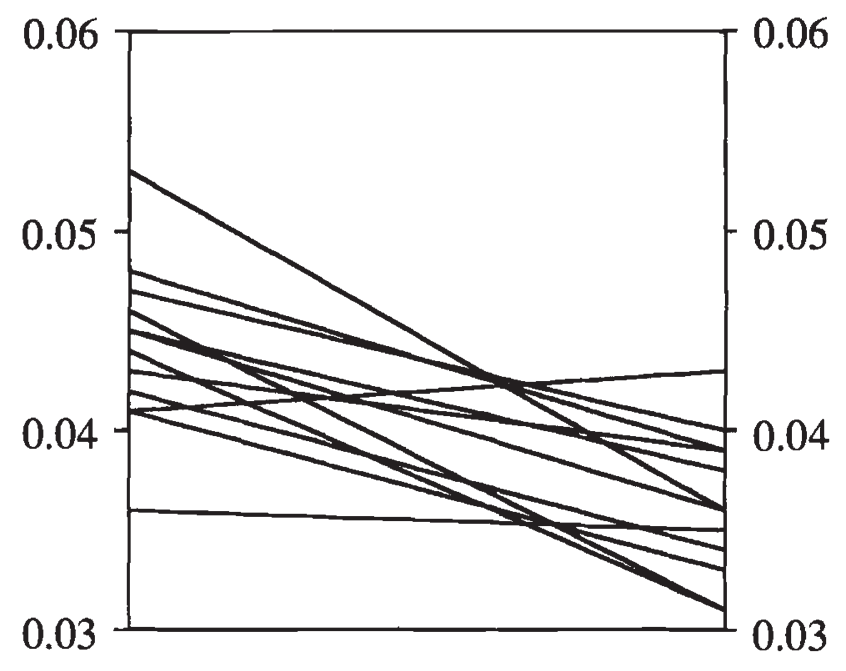

\section{Male pupal weight on blue cohosh $(\mathrm{g})$ \\ Male pupal weight on thistle $(\mathrm{g})$}

Fig. 1 Variation among full-sib families for male pupal weight. Mean pupal weight for each full-sib family on blue cohosh is shown on the left axis with the corresponding mean of sibs reared on thistle on the right axis. Lines connect the means for each family. Nonparallelism is the expression of genotype $\times$ host plant interaction.

were detected (male larval period: $r_{\mathrm{s}}=0.200$, $P>0.05$; pupal weight: $r_{\mathrm{s}}=0.119, P>0.05$; adult body length: $r_{\mathrm{s}}=0.077, P>0.05$; female larval period: $r_{\mathrm{s}}=0.182, P>0.05$; pupal weight: $r_{\mathrm{s}}=0.105$, $P>0.05$; adult body length: $\left.r_{\mathrm{s}}=0.434, P>0.05\right)$.

The calculated genetic correlation was in agreement with the above results. Estimated values of correlation coefficients based on family means with their 95 per cent confident limits are presented
Table 3 Genetic correlation estimates in the herbivorous ladybird beetle Epilachna pustulosa between the same characters across different host plants with their 95 per cent confident limits in parentheses (see text for details)

\begin{tabular}{lcc}
\hline & Male & Female \\
\hline Larval duration & -0.001 & -0.324 \\
& $(-0.392,0.391)$ & $(-0.911,0.721)$ \\
Pupal weight & 0.071 & 0.190 \\
& $(-0.276,0.402)$ & $(-0.552,0.762)$ \\
Body length & 0.129 & 0.346 \\
& $(-0.524,0.686)$ & $(-0.216,0.746)$ \\
\hline
\end{tabular}

All estimates are significantly different from complete correlation ( -1 or 1$)$, but not significantly different from 0 .

(Table 3). All estimates were not significantly different from zero, but were significantly different from complete correlations (i.e. 1 or -1 ).

From the analysis of variance on characters of ladybirds reared on thistles and blue cohosh separately, significant genotypic variation was detected in each case (Table 4).

\section{Discussion}

The purpose of this study was to see how fitness components on one host are genetically correlated with analogous components on a different host, and whether different genotypes are favoured in each different host plant environment. With the expected mean squares in the present statistical model, the family main effect variance provides a statistical test for the covariance term of the fitness components 
Table 4 Analysis of variance of developmental traits in the herbivorous ladybird beetle Epilachna pustulosa reared on thistle (A) or blue cohosh (B) and tested on each host plant separately

\begin{tabular}{|c|c|c|c|c|c|c|c|c|c|}
\hline \multirow[b]{2}{*}{ Source } & \multicolumn{3}{|c|}{ Larval duration } & \multicolumn{3}{|c|}{ Pupal weight } & \multicolumn{3}{|c|}{ Body length } \\
\hline & d.f. & SS & $F$ & d.f. & SS & $F$ & d.f. & SS & $F$ \\
\hline \multicolumn{10}{|l|}{ A. Thistle } \\
\hline Sex & 1 & 14.708 & 3.379 & 1 & 1076.196 & $3.493^{*}$ & 1 & 0.502 & $6.505^{*}$ \\
\hline Family & 12 & 230.318 & $4.410^{* *}$ & 12 & 174.806 & $6.808^{* *}$ & 12 & 3.936 & $4.252 * *$ \\
\hline Error & 64 & 278.571 & & 64 & 25.675 & & 62 & 4.783 & \\
\hline \multicolumn{10}{|c|}{ B. Blue cohosh } \\
\hline Sex & 1 & 0.295 & 0.181 & 1 & 0.021 & $11.071^{* *}$ & 1 & 1.586 & $34.807^{* *}$ \\
\hline Family & 12 & 94.624 & $4.827^{* *}$ & 12 & 0.106 & $4.747^{* *}$ & 12 & 1.492 & $2.728^{* *}$ \\
\hline Error & 106 & 173.157 & & 106 & 0.197 & & 106 & 4.784 & \\
\hline
\end{tabular}

${ }^{*} P<0.05,{ }^{* *} P<0.01$.

across habitat environments (Fry, 1992). No significant effect was found in this study. The actual estimates of genetic correlations were close to zero and differed significantly from -1 and +1 . Thus, both analyses indicate no genetic correlation between the fitness components on the two different host environments. With these genetic properties, selection on the present physiological mechanisms would neither facilitate nor reduce the ability to exploit the other host plant.

The form of the reaction norms suggests some changes in relative rank position when genotypes were reared on the two hosts. Rank correlations based on family mean variance were not significant for any variable. On the other hand, among-family variation was detected for all variables when statistical analyses were made for each host resource. Therefore, the present results would support the idea that under directional selection for higher values of the characters, different genotypes are selected on different host plants, and substantial genetic variation for growth performance is maintained among the individuals on each host plant. These lines of reasoning indicate that substantial portions of phenotypic plasticity result from genotype-dependent environmental effects.

One aim of this study was to see whether negative genetic correlations are observed between growth performance on totally different food plants in an insect species that varies in host plant utilization. The results indicate that the physiological systems responsible for the growth performance on different plants are genetically rather independent. Despite the difference in host plant environments, trade-off relationships were not found.
Because the ability to exploit hosts is unlikely to be constrained by the present physiological characters in this population, host plant utilization and host range determination will primarily be influenced by behavioural and ecological factors such as oviposition preference (if one exists), migration among host resources and abundance of host resources. This view is consistent with studies that stress the role of behaviour in host determination (Jaenike, 1978, 1990; Courtney, 1983; Iwasa et al., 1984; Singer et al., 1988, 1989; Conner, 1991; Lederhouse et al., 1992). The genetic basis for these behavioural factors and their associations with physiological performance need to be investigated.

Genetic correlation between performance on different hosts has been estimated in many species (Rausher, 1984; Via, 1984; Hare \& Kennedy, 1986; Futuyma \& Philippi, 1987; James et al., 1988; Jaenike, 1989; Fox, 1993), but only a few revealed the expected negative correlations (Via, 1991). One explanation for the lack of negative correlation is that the antagonistic relation is generally absent between the performance on different hosts (Butlin, 1987; Futuyma \& Philippi, 1987; Bernays \& Graham, 1988), no matter how different the chemical characteristics and physiological systems.

A negative genetic correlation is not necessarily expected if the population has only recently shifted to a host plant and the plant environment is still novel to the population. At the beginning of the insect-plant relationship, alleles affecting the growth performance of insects on the novel host are expected to be randomly associated with alleles affecting the performance on the established hosts, and negative genetic correlation is expected only 
when a population has reached genetic equilibrium on two hosts (Joshi \& Thompson, 1995). Although at least 40 years (= generations) have passed since the Sapporo population was first observed to utilize both of the plant species (Kurosawa, 1953; Katakura, 1974), it is not certain whether the present population has experienced sufficient selection in both plant environments and reached a genetic equilibrium.

Another explanation for the apparent lack of negative genetic correlations might lie in the experimental conditions used. Our conditions may have unintentionally imposed selection on the experimental population for overall viability in the novel conditions (Service \& Rose, 1985). This would yield overestimates of genetic correlations, and any discussion based on these estimated genetic properties may lead to erroneous conclusions. For this reason, the results obtained should be interpreted cautiously.

Variation in habitat use among local populations is known in $E$. pustulosa. The population collected from a suburb of Sapporo City indicates a close association with blue cohosh, as shown in the present study. Populations from other localities appear to be dependent mainly on thistle, even though blue cohosh is present in the locality (Katakura, 1981; Hoshikawa, 1983). Thus, the insectplant relationship seems to be specific to each local population. If the genetic structure of ladybird populations reflects host plant variation, comparative study of genetic properties among different populations may provide us with evidence of local adaptations and have implications for the potential of herbivorous insects to coevolve with their host plants (Michalakis et al., 1993).

\section{Acknowledgements}

We express our sincere thanks to A. Osugi for assistance throughout this experiment and to $\mathrm{K}$. Tsuji and S. Higashi for comments on the manuscript. Two anonymous referees improved the manuscript very much. This work was supported by JSPS Research Fellowships to H. Ueno.

\section{References}

BERNAYS, E. AND GRAHAM, M. 1988. On the evolution of host specificity in phytophagous arthropods. Ecology, 69, 886-892.

BUSH, G. L. 1969. Sympatric host race formation and speciation in fungivorous flies of the genus Rhagoletis (Diptera, Tephritidae). Evolution, 23, 237-251.
BUTLIN, R. 1987. A new approach to sympatric speciation. Trends Ecol. Evol., 2, 310-311.

CONNER, E. F. 1991. Colonization, survival, and causes of mortality of Cameraria hamadryadella (Lepidoptera: Gracillariidae) on four species of host plants. Ecol. Entomol., 16, 315-322.

COURTNEY, S. P. 1983. Models of host plant location by butterflies: the effect of search images and searching efficiency. Oecologia, 59, 317-321.

FALCONER, D. S. 1989. Introduction to Quantitative Genetics, 3rd edn. John Wiley and Sons, New York.

FOX, C. w. 1993. A quantitative genetic analysis of oviposition preference and larval performance on two hosts in the bruchid beetle, Callosobruchus maculatus. Evolution, 47, 166-175.

FRY, J. D. 1992. The mixed-model analysis of variance applied to quantitative genetics: biological meaning of the parameters. Evolution, 46, 540-550.

FUTUYMA, D. J. AND PETERSON, S. C. 1985. Genetic variation in the use of resources by insects. Ann. Rev. Ent., 30, 217-238.

FUTUYMA, D. J. AND PHILlPPI, T. E. 1987. Genetic variation and covariation in responses to host plants by Alsophila pometaria (Lepidoptera: Geometridae). Evolution, 41, 269-279.

HARE, J. D. AND KENNEDY, G. G. 1986. Genetic variation in plant-insect associations: survival of Leptinotarsa decemlineata populations on Solanum carolinense. Evolution, 40, 1031-1043.

HOSHIKAWA, K. 1983. Host-race formation and speciation in the Henosepilachna vigintioctomaculata complex (Coleoptera, Coccinellidae) I. Host-plant ranges and food-preference types. Kontyû, 51, 254-264.

IWASA, Y., SUZUKI, Y. AND MATSUDA, H. 1984. Theory of oviposition strategy of parasitoids. I. Effects of mortality and limited egg number. Theor. Pop. Biol., 14, 350-356.

JAENIKE, J. 1978. On optimal oviposition behavior in phytophagous insects. Theor. Pop. Biol., 14, 350-356.

JAENIKE, J. 1989. Genetic population structure of Drosophila tripunctata: patterns of variation and covariation of traits affecting resource use. Evolution, 43, 1467-1482.

JAENIKE, J. 1990. Host specialization in phytophagous insects. Ann. Rev. Ecol. Syst., 21, 243-273.

JAMES, A. C., JACKUBCZAK, J., RIDLEY, M. P. AND JAENIKE, J. 1988. On the causes of monophagy in Drosophila quinaria. Evolution, 42, 626-630.

JOSHI, A. AND THOMPSON, J. N. 1995. Trade-offs and the evolution of host specialization. Evol. Ecol., 9, 82-92.

Katakura, H. 1974. Henosepilachna pustulosa feeding on

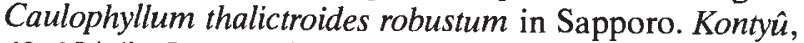
42, 394 (in Japanese).

KATAKURA, H. 1981. Classification and evolution of the phytophagous ladybirds belonging to Henosepilachna vigintioctomaculata complex (Coleoptera, Coccinellidae). J. Fac. Sci. Hokkaido University, VI (Zool.), 22, 301-378.

KATAKURA, H. 1982. Long mating season and its bearing 
on the reproductive isolation in a pair of sympatric phytophagous ladybirds (Coleoptera, Coccinellidae). Kontyû, 50, 599-603.

KUROSAWA, T. 1953. Notes on the food-plants of Epilachna pustulosa Kôno (Coleoptera, Coccinellidae). Oyô-Kontŷu, 9, 12-15 (in Japanese).

LANDE, R. 1979. Quantitative genetic analysis of multivariate evolution, applied to brain:body size allometry. Evolution, 33, 402-416.

LANDE, R. AND ARNOLD, s. 1983. The measurement of selection on correlated characters. Evolution, 37, 1210-1226.

LEDERHOUSE, R. C., AYRES, M. P., NITAO, J. K. AND SCRIBER, J. M. 1992. Differential use of lauraceous hosts by swallowtail butterflies, Papilio troilus and P. palamedes (Papilionidae). Oikos, 63, 244-252.

MICHALAKIS, Y., SHEPPARD, A. W., NOËL, V. AND OLIVIERI, I. 1993. Population structure of a herbivorous insect and its host plant on a microgeographic scale. Evolution, 47, $1611-1616$.

NAKANO, s. 1985. Sperm displacement in Henosepilachna pustulosa (Coleoptera, Coccinellidae). Kontŷu, 53, 516-519.

RAUSHER, M. D. 1984. Tradeoffs in performance on different hosts: evidence from within- and between-site variation in the beetle Deloyala guttata. Evolution, 38, 582-595.

SERVICE, P. M. AND ROSE, M. R. 1985. Genetic covariation among life history components: the effect of novel environments. Evolution, 39, 943-945.

SINGER, M. C., NG, D. AND THOMAS, C. D. 1988. Heritability of oviposition preference and its relationship to offspring performance within a single insect population. Evolution, 42, 977-985.

SINGER, M. C., THOMAS, C. D., BILLINGTON, H. L. AND PARMESAN, C. 1989. Variation among conspecific insect populations in the mechanistic basis of diet breadth. Anim. Behav., 37, 751-759.

SOKAL, R. R. AND ROHLF, F. J. 1981. Biometry, 2nd edn. Freeman, San Francisco.

STEARNS, s. C. 1992. The Evolution of Life Histories. Oxford University Press, New York.

VIA, s. 1984. The quantitative genetics of polyphagy in an insect herbivore. II. Genetic correlations in larval performance within and among host plants. Evolution, 38, 896-905.

VIA, s. 1990. Ecological genetics and host adaptation in herbivorous insects: the experimental study of evolution in natural and agricultural systems. Ann. Rev. Ent., 35, 421-446.

VIA, s. 1991. The genetic structure of host plant adaptation in a spatial patchwork: demographic variability among reciprocally transplanted pea aphid clones. Evolution, 45, 827-852.

VIA, S. AND LANDE, R. 1985. Genotype-environment interaction and the evolution of phenotypic plasticity. Evolution, 39, 505-522. 